\title{
A hospital based clinico-pathological study of soft tissue tumors
}

\author{
Bhosle R.V ${ }^{1}$, P. Sreenivasa ${ }^{2}$ \\ ${ }^{1}$ Assistant Professor, ${ }^{2}$ Associate Professor, Department of Surgery, MNR Medical College \& Hospital, Sangareddy, \\ Telangana, India.
}

Corresponding Author: Dr. P. Sreenivasa, Associate Professor, Department of Surgery, MNR Medical College \& Hospital, Sangareddy, Telangana. Email: drsreenivasap@gmail.com

\begin{abstract}
Background: Soft tissue sarcomas can develop from soft tissues like fat, muscle, nerves, fibrous tissues, blood vessels, or deep skin tissues. They can be found in any part of the body, commonly seen in the trunk, head and neck area, internal organs, and the area in back of the abdominal cavity (known as the retroperitoneum). Most of them develop in the arms or legs. Aim: The study was conducted to know the incidence, location of soft tissue tumors at different age group individuals and to analyze the various types and subtypes of soft tissue tumors. Materials \& Methods: Total of 124 cases of soft tissue lesions were analyzed retrospectively and prospectively in a period of 1.5 years. The prospective study was conducted in the department of surgery and Institutional ethical committee approval was obtained. A detailed clinical data was collected by using the standard data sheet and biopsy specimens were sent to pathology department for histopathological evaluation. Results: The present clinicopathological study included 124 soft tissue tumor cases in different age groups. The occurrence of age wise soft tissue tumors has been depicted in table 1. Out of 124 soft tissue tumors, 97 were benign type, 27 were malignant variety. Conclusion: The present hospital-based study reports data of various types of benign and malignant soft tissue tumors, their relative incidence in male and female and their distribution with respect to the anatomical location of human body. Benign tumors required simple excision, but aggressive benign myxoid tumors and malignant soft tissue tumors require wide surgical excision and close follow up.
\end{abstract}

Key words: Soft tissue tumors, Benign, Malignant, Histopathological.

\section{Introduction}

A sarcoma is a type of cancer that develops from certain tissues, like bone or muscle. Mesenchymal tumors also known as soft tissue tumors arise from embryonic mesoderm and include those of connective tissue, endothelial, hematopoietic, and lymphoid and muscle origin [1]. Soft tissue sarcomas can develop from soft tissues like fat, muscle, nerves, fibrous tissues, blood vessels, or deep skin tissues [2].

They can be found in any part of the body. Most of them develop in the arms or legs. They can also be found in the trunk, head and neck area, internal organs, and the area in back of the abdominal cavity (known as the retroperitoneum). Sarcomas are not common tumors, and most cancers are the type of tumors called carcinomas. The group of soft tissue tumors mainly includes fibromatoses, fibro sarcomas, histiocytomas, neurofibrosarcomas,rhabdomyosarcomas, liposarcomas,

Manuscript Received: $28^{\text {th }}$ January 2018

Reviewed: $6^{\text {th }}$ February 2018

Author Corrected: $14^{\text {th }}$ February 2018

Accepted for Publication: $18^{\text {th }}$ February 2018 synovial cell sarcomas and meningiomas [3]. Soft tissue sarcomas compared with carcinomas and other neoplasms are relatively rare and constitute less than $1 \%$ of all the cancer. It may occur anywhere in the body but most of the tumors arise from large muscle of extremities, the chest wall, the mediastinum and the retroperitoneum [4]. The soft tissue tumors affect at any age and like carcinomas are more common in older patients, about $40 \%$ affect persons 55 years or older $[3,4]$.

The development of unusual malignant soft tissue tumors may be associated with genetic factors, environmental factors, irradiation, viral infections and immune deficiency [5]. Some of the studies reported that the sarcoma arises from surgical procedures or thermal or acid burns, fracture site and vicinity of plastic or metal implant in soft tissues. Environmental factors like asbestos, phenocyacetic acid, chlorophenols and their contaminants are also been responsible for the origin of sarcomas [6]. Among all, the soft tissue 
tumors induced by radiation are most common. It is difficult to estimate the exact percentage of post radiation sarcomas but range from $0.03 \%$ to $0.80 \%$ quoted by several studies $[5,7]$.

The biological activity of these tumors varies from benign localized tumors, to benign locally aggressive, to malignant metastatic types. Several diagnostics methods are available for identification and differentiation of soft tissue tumors like light microscopy, special stains and immunohistochemistry. Most of the studies describes that the large majority of soft tissue tumors are benign but their malignant counterparts are life threatening and may pose a significant diagnostic and therapeutic challenge since there are more than 50 histological subtypes of soft tissue tumors [8].

Soft tissue tumors comprise a large heterogeneous group of mesenchymal neoplasms that are classified according to their normal tissue counterpart. These tumors vary in their incidence, clinical presentation, and exhibit a wide range of histomorphological features [9]. Histopathological examination is the gold standard for the diagnosis of soft tissue tumors. It helps to predict the prognosis and thereby helps in the proper management of the patient [10]. The study was conducted with the aim to study the incidence, location of soft tissue tumors at different age group individuals and to analyze the various types and subtypes of soft tissue tumors.

\section{Materials \& Methods}

The present prospective study was conducted in the Department of General Surgery, MNR Medical College \& Hospital, Sangareddy, and Telangana from July, 2016 to December, 2017. Total of 124 cases of soft tissue lesions were analyzed retrospectively and prospectively in a period of 1.5 years. The study was scrutinized and approved by the Institutional Ethical Committee. Patients with peripheral soft tissue tumors like those of the upper and lower extremities, trunk, head and neck were included in the study.

Those with visceral and retroperitoneal soft tissue tumors were excluded from the study. A detailed clinical data of the each case including age, sex, anatomical location, various diagnosing modalities and histopathological examination were collected using the standard data sheet.

The surgical biopsy specimens of both incision and excision biopsy materials of different soft tissue tumors were collected and transferred in $10 \%$ neutral formalin for fixation for $24 \mathrm{hrs}$. The physical examination of specimen was carried out to know the macroscopic findings like size, shape, color, extension and consistency. The samples were sent to the department of pathology for histopathological evaluation. Sections were stained using conventional haematoxylin and eosin stain and studied by light compound microscopy.

\section{Results}

The present clinicopathological study included 124 soft tissue tumor cases in different age groups. The occurrence of age wise soft tissue tumors has been depicted in table 1. Out of 124 soft tissue tumors, 97 were benign type, 27 were malignant variety (Figure 1).

The anatomical distribution of cases are adipose tissue $27.4 \%$, fibrous $13.7 \%$, striated muscle $8.8 \%$, smooth muscle $9.6 \%$, vascular $19.3 \%$, synovial $6.4 \%$ and neural tissue $14.5 \%$ were seen in current study (Figure 3 ). The gender wise distributions of benign and malignant tumors are impregnated in figure 2.

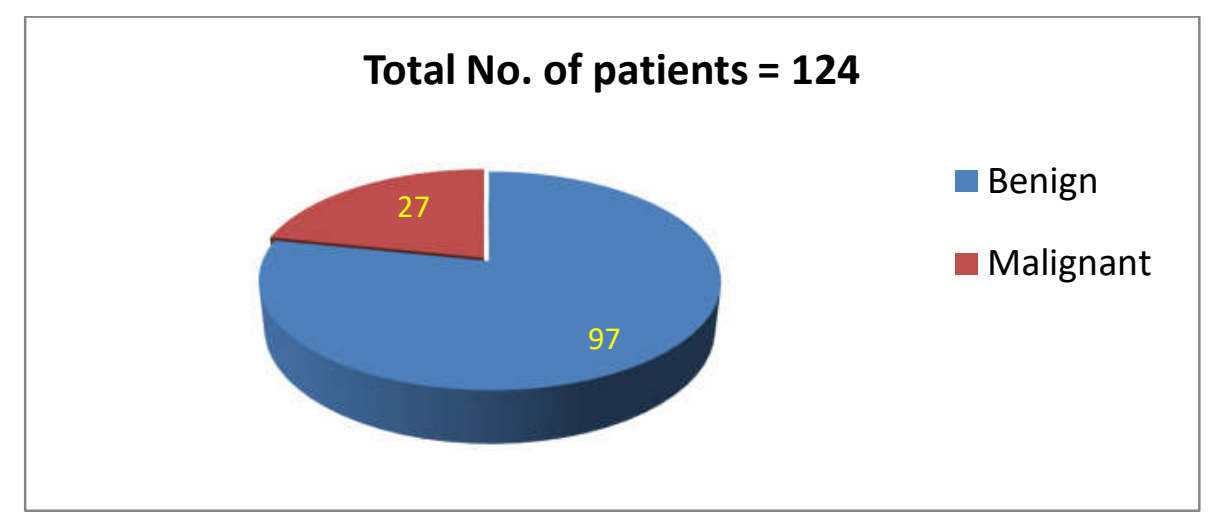

Figure-1: Frequency of benign and malignant type among soft tissue tumors. 
Original Research Article

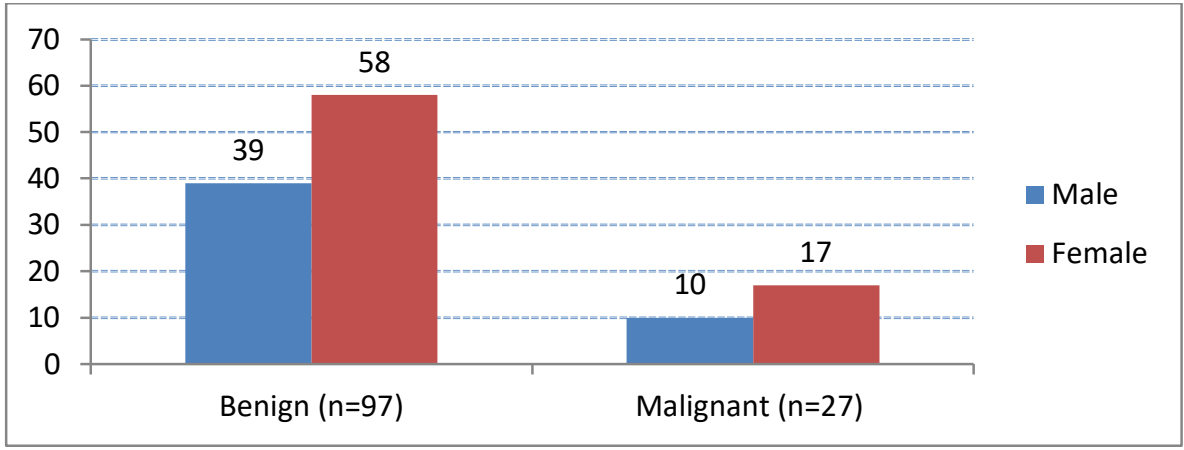

Figure-2: Frequency of benign and malignant soft tissue tumors in males and females.

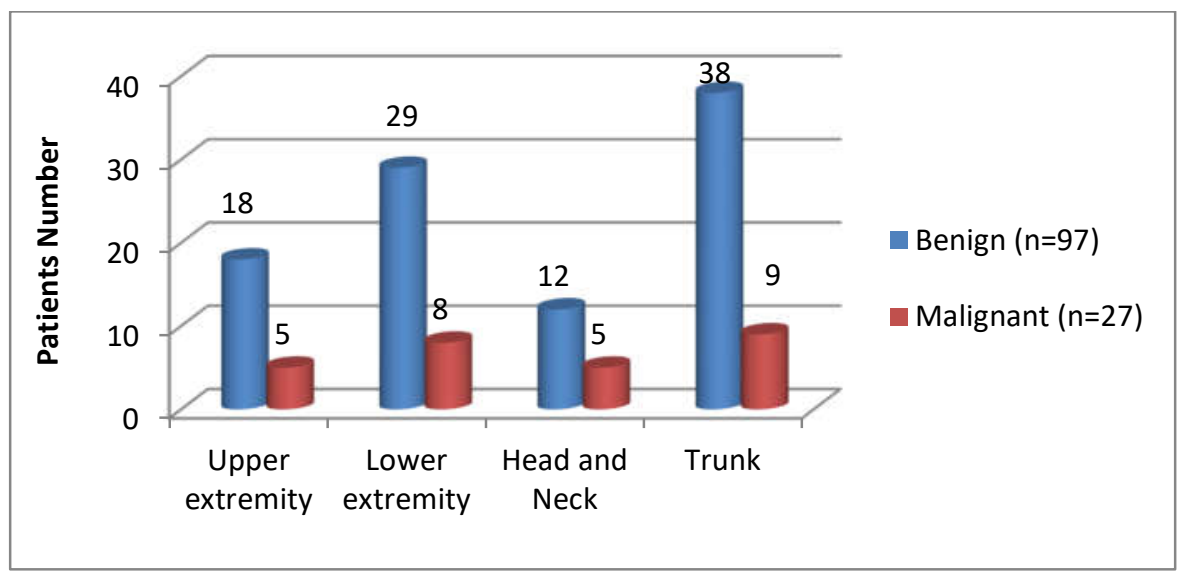

Figure-3: Distribution of soft tissue tumors

Table-1: Age wise distribution of soft tissue tumors.

\begin{tabular}{|c|c|c|c|c|c|c|c|}
\hline \multirow{2}{*}{$\begin{array}{c}\text { Histological } \\
\text { type }\end{array}$} & \multicolumn{6}{|c|}{ Age in Years } & \multirow{2}{*}{ Totaln(\%) } \\
\cline { 2 - 8 } & $\mathbf{5 1 0}$ & $\mathbf{1 1}$ to 20 & $\mathbf{2 1}$ to 30 & $\mathbf{3 1}$ to 40 & $\mathbf{4 1}$ to 50 & $>\mathbf{6 0}$ & \\
\hline Adipose tissue & 3 & 2 & 3 & 8 & 11 & 7 & $34(27.4)$ \\
\hline Fibrous & 1 & 2 & 2 & 4 & 5 & 3 & $17(13.7)$ \\
\hline Striated muscle & 1 & 1 & 2 & 2 & 3 & 2 & $11(8.8)$ \\
\hline Smooth muscle & 1 & 1 & 2 & 3 & 3 & 2 & $12(9.6)$ \\
\hline Vascular & 3 & 2 & 4 & 5 & 4 & 6 & $24(19.3)$ \\
\hline Synovial & 1 & 0 & 2 & 1 & 2 & 2 & $08(6.4)$ \\
\hline Neural tissue & 1 & 2 & 3 & 5 & 4 & 3 & $18(14.5)$ \\
\hline
\end{tabular}

\section{Discussion}

The tumors arise from non-epithelial, extra skeletal tissues of the body are defined as soft tissue tumors. It is represented by the voluntary muscles, fat and fibrous tissue, along with the vessels serving these tissues. Identification or definition of soft tissue tumors by physical examination may be difficult. Most of the tumorsare firmer than the surrounding soft tissues and are often attached to bone, fibrous membranes, or even vascular or neural structures. Except for the liposarcoma, most soft tissue tumors are easily distinguished from normal fat in the subcutaneous layers, but they may appear to be related to recent or even earlier trauma [10]. The tumors may be tender, particularly if they are surrounded by neural or vascular structures or if they become large enough to compress or cause a significant stretching of a muscular structure such as the deltoid or quadriceps.

The current study with frequency rate of $78.2 \%$ of benign soft tissue tumors are slightly less than the reports of Sonal Jain [11], Jain pramila et al [12] and Agaravat et al [13] with the incidence rate of $90.6 \%$ and $86 \%$ respectively. The malignant soft tissue tumors found in $21.7 \%$ of the cases in present study, the results 
Original Research Article

are high as compared to $9.4 \%$ and $6 \%$ in the reports of Sonal Jain [11], Jainpramila et al [12] and Agaravat et al [13]. Among cases of soft tissue tumors 49 were found in males, 75 were found in females. The soft tissue tumors are found more in females than males. Soft tissue tumors of benign and malignant had female predominance. Similar results are reported by Agaravat et al [13], Mirza et al [14], and Janaki et al [15]. The ratio of $\mathrm{M}: \mathrm{F}$ of benign soft tissue tumors reported by Sonal Jain [11] are not in agreement with present study.

The anatomical locations of soft tissue tumors are evaluated. The most common anatomical location affected with soft tissue tumors is trunk followed by lower extremities, upper extremities, head and neck. Sharon and Weiss [16] reported that extremities are the most common sites of soft tissue tumors followed by retroperitoneum. Jain et al presented $35.4 \%$ of soft tissue tumors in extremities and chest; Venkatraman [17] study reported 11 cases in lower extremities. The study correlated with Bennet KW [18] and Kransdorfet al [19] which had strong predilection for lower extremities, abdomen and trunk.

In concordance with the previous studies, most common soft tissue tumors is adipose tissue origin (34 cases), second most common is vascular tumors (24 cases) $[14,15,16,17]$. The general complaint of the majority of patients was swelling followed by pain which is in consistent with other studies. The management of soft tissue tumors depends on whether the tumors are benign or malignant. For a clinically localized primary or recurrent soft tissue sarcoma, surgery is the ultimate therapy. Complete local excision is required to remove the benign soft tissue tumors for adequate treatment.

Wide excision is necessary for management of nonmetastasizing lesions, like desmoid type fibromatosis [16]. Wide excision is the procedure of choice for lower-grade sarcomas whereas for higher grade sarcomas, multimodal therapy is preferred, including surgery, radiotherapy and/or chemotherapy $[17,18,19]$.

\section{Conclusion}

The present hospital-based study reports data of various types of benign and malignant soft tissue tumors, their relative incidence in male and female and their distribution with respect to the anatomical location of human body. The results of the study show that $124 \mathrm{soft}$ tissue tumor cases operated in department of surgery and 97 tumors were benign, 27 tumors were malignant type. Benign tumors required simple excision, but aggressive benign myxoid tumors and malignant soft tissue tumors require wide surgical excision and close follow up. Even though clinical, morphological and anatomical location features are important for diagnosis; Histopathological examination of biopsy is a gold standard to classify the type of tumors and it plays crucial role in management and prognosis of soft tissue tumor cases. However, it would more prudent if future studies include large number of sample size, geographical data, size of the tumors at different anatomical location and its type.

Conflict of interest: None declared.

Funding: Nil, Permission from IRB: Yes

\section{References}

1. Fletcher CDM, Unni KK, Mertens F (Eds): WHO classification of tumors:Pathology and genetics of soft tissue and bones. IARC press, Lyon 2002;p12-6.

2. Gerrand $\mathrm{CH}$, Bell RS, Wunder JS, et al. The influence of anatomic location on outcome in patients with soft tissue sarcoma of the extremity. Cancer. 2003; 97: 485-492.

3. Epstein HD. Fine-needle aspiration of soft tissue lesions. Pathology (Phila). 1996;4(2):463-92.

4. Liebl LS, Elson F, Quaas A, Gawad KA, Izbicki JR. Value of repeat resection for survival in pulmonary metastases from soft tissue sarcoma. Anticancer Res. 2007; 27:2897-2902.

5. Lavelle, S.M., PW Walton and Maura Mhic Lomhair. Effect of irradiation, asbestos and chemical carcinogenesis on incidence of sarcomas on implant. Technology and Health Care.2004;12:217-223.

6. Antman K, Crowley J, Balcerzak SP, Rivkin SE, Weiss GR, Elias A, Natale RB, Cooper RM, Barlogie B, Trump DL, et al. An intergroup phase III randomized study of doxorubicin and dacarbazine with or without ifosfamide and mesna in advanced soft tissue and bone sarcomas. J Clin Oncol. 1993 Jul;11(7):1276-85.

7. Calhoun KH, Bradfield JJ, ThompsonC. Liposuctionassisted excision of cervicofacial lipomas. Otolaryngol Head Neck Surg. 1995 Oct;113(4):401-3.

8. Allen PW. The diagnosis, classification and grading of soft tissue tumors. J Orthop Sci.1996;1:148-56.

9. Epstein HD. Fine-needle aspiration of soft tissue lesions. Pathology (Phila). 1996;4(2):463-92. 
10. Myhre-Jensen O. A consecutive 7-year series of 1331 benign soft tissue tumours. Clinicopathologic data. Comparison with sarcomas. Acta Orthop Scand. 1981 Jun; 52 (3):287-93.

11. Sonal Jain and Kirit Jadav. Histopathology of soft tissue tumors in association with immunohistochemistry. International Journal of Biomedical and Advance Research 2017; 8(08): 327-336.

12. Jain Pramila, Shrivastava Archana, Malik Reeni. Clinicomorphological assessment of soft tissue tumors. Scholars journal of applied medical sciences. Sch. J. App. Med. Sci., 2014; 2(2d): 886-890.

13. Agaravat, A.H., Dhruva, G.A. And Parmar, S.A. Histopathology study of humans soft tissue tumors and tumour like lesions. Journal of Cell and Tissue Research, 2010; 10(2):2287-2292.

14. Mirza Asif Baig et al. Histological study of soft tissue tumor, 2005: 1039- 1049 Enzinger \& Weiss's Soft Tissue Tumors; 5 th Edi.
15. Janaki M, Morphological study of soft tissue tumors, International journal of Research in Health Sciences. Apr-Jun 2015; 3(2): 364.

16. Weiss SW, Rao VK. Well-differentiated liposarcoma (atypical lipoma) of deep softtissue of the extremities, retroperitoneum, and miscellaneous sites. A follow-up study of 92 cases with analysis of the incidence of "dedifferentiation".Am J Surg Pathol. 1992 Nov; 16 (11):1051-8.

17. Venkatraman J, Rathna S, Dhananjay S. Kotasthane, Govindaraj. Clinicopathological Study of Malignant Soft Tissue Tumors. 2014 Month : December Volume : 3 Issue : 71 Page : 15083-15089.

18. Bennert KW, Abdul-Karim FW. Fine needle aspiration cytology vs. needle core biopsy of soft tissue tumors. A comparison. Acta Cytol. 1994 May-Jun; 38(3) :381-4.

19. Kransdorf MJ. Malignant soft-tissue tumors in a large referral population: distribution of diagnoses by age, sex, and location. AJR Am J Roentgenol. 1995 Jan; 164 (1):129-34.

\section{How to cite this article?}

Bhosle R.V, P. Sreenivasa. A hospital based clinico-pathological study of soft tissue tumors. Surgical Update: Int J surg Orthopedics.2018;4(1):24-28. doi:10.17511/ijoso.2018.i01.05. 